\title{
Adverse Effects of Dietary Habits on Menstrual Disorders in Young Women
}

\author{
Tomoko Fujiwara*, ${ }^{, 1}$, Natsuyo Sato $^{2}$, Hiroyo Awaji ${ }^{2}$ and Rieko Nakata ${ }^{2}$ \\ ${ }^{1}$ Faculty of Home Economics, Ashiya College, Ashiya, ${ }^{2}$ Department of Food Science and Nutrition, Nara Women's \\ University, Nara, Japan
}

\begin{abstract}
It has been accepted that food customs are closely associated with quality of life in women of the reproductive age. Food customs are speculated to not only influence the present life style but also to induce gynecological disorders such as dysmenorrhea and irregular menstruation. Although there is no constant definition of regular or normal menstruation, epidemiologic evaluation of menstrual cycle has been becoming an important issue. In addition, latent development of organic diseases such as endometriosis, which are accompanied by dysmenorrhea, is a concern under the current nutritional environment in young women. Thus, it is an important issue to evaluate the present situation of eating habits in young women and estimate the influence of these habits on the quality of reproductive functions. Therefore, in this review, recent articles that are concerned with these issues have been reevaluated.
\end{abstract}

Keywords: Dysmenorrhea, food intake, irregular menses, menstrual disorder, nutrition, reproduction.

\section{INTRODUCTION}

Dietary habits are fundamental factors that influence human life styles and individual quality of life (QOL). In addition, the adverse effects of environmental hormones or toxins on human health, which will be manifested in later life, have been pointed out [1-3]. Thus, dietary habits in young women may determine their QOL in subsequent middle or old age and should be evaluated from the perspective of total benefit throughout whole life.

In Japan, widespread consumption of fast food, skipping of food intake, and the shift from Japanese to Western foods are increasing among young women $[4,5]$. One of the most common nutritional issues among young women in Japan is poor energy intake and/or inappropriate food selection due to dietary limitations for cosmetic purposes, which can lead to poor intake of protein, carbohydrate and essential fatty acids along with diet-related psychological stress [5]. These factors are speculated to influence not only the present life style but also future medical disorders such as cardiovascular and metabolic diseases [6, 7]. Furthermore, menstrual and reproductive factors have also been proposed to be associated with malignant diseases in the uterus as well as in other organs [8]. Accordingly, it is important to evaluate the present situation of eating habits in young women and estimate their influence on menstrual disorders.

Although epidemiologic evaluation of menstrual cycle is an important, it is difficult to precisely determine the normal length of menstrual cycles in individuals with cyclic variability because there is considerable variation in menstrual cycles among women [9]. When researchers strictly exclude women with irregular menstrual cycles, they tend to rigidly select the group with a narrow range of menstrual cycles as normal menstrual intervals from $25-28$ to 32 days [10]. In

*Address correspondence to this author at the Faculty of Home Economics, Ashiya College, 14-10 Rokurokuso-cho, Ashiya, 659-8511, Japan; Tel: 81797-23-0663; Fax: 81-797-38-6705; E-mail: tomokof@bd5.so-net.ne.jp contrast, if researchers want to strictly select the group with irregular menstrual cycles, they will define the normal spectrum as a rather broader range, frequently 20 to 40 days [11].

Based on this background, we think that the proposal of standard normal menstrual function for epidemiologic evaluation is necessary for adequate assessment of young women health. In addition, the relationship between food customs and menstrual dysfunction has been becoming important issue in the world. Therefore, this review article described the optimal definition of regular or normal menstruation according to the aims and subjects of the study and possible influence of food intake on menstrual disorders in young women.

\section{NORMAL MENSTRUAL CYCLE}

Menstruation is defined as the periodic discharge of blood, mucus, and cellular debris from the uterine mucosa. The menstrual cycle is a repetitive phenomenon caused by the interaction of the hypothalamic-pituitary-ovarian system and can be divided into three stages: the follicular phase, recruitment and growth of a new follicle; the ovulatory period, at which time an oocyte is released into the peritoneal cavity; the luteal phase, at which time a newly formed corpus luteum produces progesterone [12]. The cycle is mainly regulated by the hypothalamus, in which gonadotropinreleasing hormone $(\mathrm{Gn}-\mathrm{RH})$ is released in pulses to stimulate pituitary gonadotropes to secrete follicle-stimulating hormone (FSH) and luteinizing hormone (LH). These gonadotropins in turn promote follicular development with ovulation and corpus luteum formation in the ovary, inducing steroid hormone production. The estradiol-positive feedback loop causes the midcycle Gn-RH and LH surges to induce ovulation in the matured preovulatory follicle.

Since positive estrogen feedback system on the hypothalamus and pituitary is developing throughout puberty, menstruation following menarche is usually irregular and/or anovulatory. The frequency of ovulation gradually increases as puberty progresses, but it is common for $25-50 \%$ of adolescents to still be anovulatory 4 years after menarche 
lescents to still be anovulatory 4 years after menarche [13]. Several years after menarche, transient disturbances of progesterone secretion in the luteal phase are commonly observed in adolescents [13]. The average age of menarche in Western European countries appears to have declined over the past 150 years from over 16 to under 14 years [14]. In the United States, the normal age range of menarche is 9.1-17.7 years with a median of 12.8 years $[15,16]$. There is no evidence that the age of menarche has decreased over the past 30 years in USA [17]. The declining age of puberty has been attributed to improved standards of living such as adequate nutrition and health care $[17,18]$.

Menstrual cycle length is mainly determined by the rate and quality of follicular growth and development. Although many textbooks in reproductive medicine describe typical menstrual cycle as 28 days [19], there is limited discussion regarding the definition of normal range of the regular menstrual cycle. This is probably because there is considerable variation in menstrual cycles among women.

More than one hundred years ago, it was reported that mean and/or median menstrual cycles are between 28 to 30 days [20, 21]. In 1939, Arey analyzed 12 reports from 1989 to 1937 and reported that the mean interval of menstrual cycles was 28.4 days [22]. In 1942, Haman showed an almost identical distribution of menstrual cycle by analyzing 150 normal housewives [23]. In 1968, the mean of menstrual intervals was reported to be 29.1 days by analyzing 2,316 women [24]. In this study, when the study population was limited to women having menstrual intervals between 15 and 45 days, the mean of menstruation was re-calculated as 28.1 days.

Treloar et al. demonstrated that the mean of the menstrual intervals gradually decreased from 30 to 26 days along with the narrowing of the 90 percentile ranges [25]. Variability in cycle length among females is in principle due to the varying number of days required for follicular growth and development. The key hormone was shown to be inhibin, not estrogen [26]. In the late 30's years when FSH increases and inhibin decreases [27, 28], the mean length and variability of menstrual cycles become the shortest. In 1984, Lenton et al. analyzed 293 British women with ovulatory menstrual cycles and reported that mean interval of follicular phase was 12.9 days with $95 \%$ confidence limits between 10.3 to 16.3 days [29]. This study also showed that follicular phase length was significantly decreased along with aging, from 14.2 days in women aged 18-24 years old to 10.4 days in women aged 40-44 years old. In 1992, Munster et al. analyzed 3743 Danish women aged 15-44 with regular menstrual cycles and found that in women with regular menstrual cycles, the 5-95 percentile range of usual cycle length of 23-35 days in the 15-19 years age group decreased to 23-30 days in the 40-44 years age group [30]. Based on these findings, it can be concluded that the interval between menstrual periods has not been changed during a century and that the median interval is 28 days during active reproductive years [19].

\section{MENSTRUAL DISORDERS}

\section{A. Irregular Menstruation}

To predict dysfunction in the hypothalamic-pituitaryovarian axis, irregular menstruation is one of the positive clinical symptoms. Therefore, increasing attention has been paid to abnormality of the menstrual cycle in various fields. For example, the National Institute for Nursing Research in the USA has been active in developing research addressing the cause and consequences of menstrual cycle and menopause- related health problems, suggesting that menstrual cycle research is a strong area of interest in nursing science [31]. Irregular menses are also a concern among college-age women. These problems may reflect normal ovulatory menstrual symptoms or be suggestive of significant pathology that can have a major impact on future reproductive and general health [32]. In addition, by analyzing 33,434 postmenopausal women, it was reported that women having both irregular menstrual cycles and irregular menstrual bleeding had about 2-fold higher risk of hip fracture than did women who reported neither irregularity [33].

Based on the analysis of over 20 papers from 7 developing countries, Harlow and Campbell indicated that studies did not use consistent definitions of menstrual disorders and summarized the results in broad categories, defining oligomenorrhea as menstrual cycles of 35-90 days [9]. Therefore, researchers must define the optimal range of regular or normal menstruation according to the aims and subjects of the study. In general, if the researchers want to strictly select the group with irregular menstrual cycles, they will define the normal spectrum as a rather broader one. For this purpose, the range between 20 and 40 days is frequently employed [11]. Especially, to examine the effects of various factors on menstrual irregularity during early postmenarcheal age, this broad definition is used [34]. In 2003, Schneider et al. reported that fresh female military cadets had considerable menstrual irregularity. In this study, although the authors defined the normal range of menstrual length more broadly from 21 to 45 days, they found that only $12 \%$ of cadets belonged to the range within 21-45 days [35]. In contrast, when researchers want to strictly exclude women with irregular menstrual cycles, they rigidly select the group with a narrow range of menstrual cycles as normal menstrual intervals. For example, Battaglia et al. used a strict criteria of 28-32 days as regular menstrual cycles to estimate the relation between utero-ovarian ultrasonographic analyses and circulating FSH levels in female childhood cancer survivors [10]. Another recent study defined 25-32 days as regular menstrual cycle [36]. In our recent study to analyze premenstrual symptoms in college-aged women (18-20 years) in Japan, we strictly defined regular menstrual cycles as 26-32 days. Under this condition, two thirds of the students were classified into the group with regular menstruation. This population almost corresponded to the range of \pm 1 SD of the whole population, indicating that the strict selection of regular menstruation is reliable [in submission]. On the other hand, when the restriction is not so severe, researchers have defined normal menstrual length as 23-25 days to 35 days $[37,38]$.

\section{B. Dysmenorrhea}

Dysmenorrhea is an important sign of functional disturbance in the hypothalamic-pituitary-ovarian axis and subsequent local inflammation in the pelvic cavity [39-43], which also is an excellent parameter that reflects female psychophysiological status. It begins within 6-12 months from the menarche and is characterized by localized pain in the abdominal inferior quadrants. Pathophysiologically, pelvic pain 
is conducted through afferent pathways by the hypogastric sympathetic and parasympathetic nerves. However, pelvic pain is an integrated physical sense and sensitivity to pain can easily be influenced by various factors such as stress $[44,45]$, the intensity of dysmenorrhea is usually defined according to subjective complains. For example, it is classified into 3 grades (score 1, not requiring analgesic; score 2, painful, requiring analgesic; score 3 , painful, not relieved by analgesic) [4].

Hormonal disorders in ovarian function or pelvic organic diseases are mainly considered to cause dysmenorrhea [40]. Primary dysmenorrhea is derived from an abnormal increase in the contractile activity of the uterus [41]. It is usually due to functional immaturity in ovarian sex steroid hormone production that stimulates local production of chemical mediators such as prostaglandins E2, F2 and leukotrienes in the uterus during menstruation [42]. Clinically, when the matured women have dysmenorrhea without apparent signs for ovarian dysfunction such as irregular menstruation, several organic disorders such as uterine myoma should be suspected. Endometriosis is one of the most important gynecological diseases manifested as dysmenorrhea, which needs laparoscopic examination for accurate diagnosis [46]. The affected lesions are considered to gradually spread all over the pelvic cavity through periodic ovulation and menstruation, resulting in severe tissue adhesion, pelvic pain and infertility in reproductive age [46]. Dysmenorrhea is an important initial symptom for endometriosis, which causes local inflammation with pelvic pain and infertility.

\section{Premenstrual Syndrome}

Premenstrual syndrome is a multifactorial syndrome that affects adolescent girls with a high frequency. This syndrome is characterized by manifestation of pschychological disorders such as irritability, depression, and mood swings and/or somatic complaints including abdominal bloating, peripheral edema, general fatigue and acne before menstruation [47]. These symptoms are recurrent according to menstrual cycles and rapidly disappeared just after onset of menstruation. Although various etiologies of premenstrual syndrome such as elevated prolactin levels, hypoglycemia or vitamin deficiencies have been proposed, none of these theories has been definitively proven [48]. Although more than 100 symptoms and/or signs are considered to involved in premenstrual syndrome, there is no specific laboratory test to precisely diagnose premenstrual syndrome [49]. The high incidence of premenstrual syndrome in young women was recently reported showing that about $60 \%$ of adolescence complain of premenstrual syndrome based on the criteria described in the Manual of Mental Disorders-IV [50, 51].

\section{FOOD INTAKE AND MENSTRUAL DISORDERS}

\section{A. Influence of Low Calorie Intake on Menstrual Disor- ders}

Nutritional deficiency is considered one of the important factors that induces hypothalamic-pituitary-ovarian dysfunction. Recently, adolescents have tended to try to lose body weight by dietary restriction for cosmetic purpose. In Japanese young women, more than $60 \%$ college students used diet control to reduce weight despite a normal or low body mass index [52, 53]. Montero et al. reported that among
1147 urban Spanish adolescents, aged between 14 and 20 years, nearly $40 \%$ of the adolescents tried to lose weight and that attempting to lose weight is significantly associated with an increase in irregular menstruation and dysmenorrhea without a significant relation with body mass index [54]. The epidemiological study showed that circulating level of gonadal steroids is suppressed in Bushwomen except when food is plentiful and hunting activities restricted, suggesting close relationship between nutritional deficiency and hypothalamic-pituitary-ovarian suppression [55]. It has been also reported that vegetarians frequently have menstrual disturbances [56-59]. To predict dysfunction in the hypothalamicpituitary-ovarian axis, irregular menstruation is one of the positive clinical symptoms. An experimental vegetarian diet with low calorie was reported to induce menstrual cycle disorders, showing a short luteal phase [60]. In women who have diets with high in fiber, low in fat, or both, concentrations of ovarian hormones or their metabolites were shown to be lower at various points in the menstrual cycle [61-67]. Low weight and fat mass, low calorie intake and eating disorders are speculated to disturb the pulsatile secretion of pituitary gonadotropins. In Japanese women, a positive relationship between monounsaturated fat intakes and serum estrogen concentration, and an inverse relation between fiber and serum estrogen were also observed $[68,69]$. However, it should be noted that there was a unique report demonstrating that female dieters appear to make more healthy food choices than non-dieters and so may be tuning into healthy eating messages more effectively [70].

On the other hand, several studies reported that vitamin deficiency or hypoglycemia can induce premenstrual syndrome in which patients complain of irritability, constipation and edema several days before the onset of menstruation [71]. It was also reported that deficiency of vitamin B1 and magnesium may cause dysmenorrhea, suggesting supplementation of these agents can relieve menstrual symptoms [71]. Very recently, we confirmed that the frequency of irregular menstruation was increased in young women who were currently on a diet and found that the intensity of dysmenorrhea was high in those with a history of dieting in adolescence, suggesting that diet in adolescence has long-lasting adverse effects on reproductive function in young women [53]. These findings notably warn of the possibility that diet limitation in adolescence becomes a trigger for the subsequent development of organic gynecologic diseases, supporting the concept that inadequate dietary habits may influence women's QOL not only in the present but also in the future.

\section{B. Influence of Excess Calorie Intake on Menstrual Dis- orders}

It is well known that excess weight and obesity are associated with irregular menstrual cycles, which reduce fertility and increase hormone-sensitive cancers in young women [72,73]. Obesity is considered to cause abnormality of sex steroid hormone balance and serum sex hormone binding globulin level. In young women, the onset of obesity is significantly correlated with menstrual irregularities in later reproductive age. Irregular menstruation is more frequently observed in women who became obesity during puberty than in those who were obese during infancy [74]. Recently, leptin, which is a novel hormone produced mainly by adipose cells [75], was demonstrated to regulate gonadotropin 
surge during puberty, providing a new explanation for menstrual irregularities observed in obese women [76,77]. In overweight women, a low fat diet was shown to decrease symptoms of dysmenorrhea along with increasing serum sex hormone binding globulin concentration [78,79]. Furthermore, since a long-term follow-up study showed that the prevalence of type 2 diabetes was seven times higher in women with polycystic ovarian syndrome (PCOS) [80] that is frequently associated with irregular menstruation, irregular menstruation is assumed to be one of risk factors for metabolic diseases [81].

Excessive caloric intake observed in young women is frequently due to excess intake of confectionary and sweet drinks containing artificial sweeteners. It should be noted that the safety of these sweeteners on human health has not yet been proven [82]. On the other hand, Nagata et al. reported that intake of green and yellow vegetables, which are rich in carotenoids, could accelerate onset of menopause [83].

\section{The Influence of Dietary Customs on Menstrual Dis- orders}

\section{Food Skipping}

Evidence suggests that breakfast consumption may improve cognitive function related to memory, test grades, and school attendance. Breakfast as part of a healthful diet and lifestyle can positively impact children's health and wellbeing [84]. On the other hand, breakfast skipping increased during the transition to adulthood, and is associated with increased weight gain from adolescence to adulthood [85]. Schweiger et al. reported that daily eating habits significantly influence menstrual function in young women. In this study, the authors concluded that high cognitive limitation in daily eating behavior may be a risk factor for the development of menstrual disturbance in young women, showing lower serum progesterone concentration and shorter length of luteal phase [86]. We recently found that young women who skip breakfast have a significantly higher degree of dysmenorrhea symptoms than young women who eat breakfast, suggesting a positive correlation between skipping breakfast and menstrual disorders [4]. We also confirmed the previous report that breakfast-skipping induced constipation that can cause various organic disorders in the pelvic cavity $[87,88]$. Although the mechanism is completely unknown, it is possible that some factors that become deficient by breakfast skipping may be involved in the development of dysmenorrhea [4].

\section{Unsaturated Fatty Acids}

Unsaturated fatty acids were reported to be concerned with menstrual disorders. $\omega-6$ fatty acids (e.g., vegetable oil, eggs, and margarine) contribute to the formation of proinflammatory eicasanoids, such as PGE2, thromboxane A2, and leukotriene B4, whereas $\omega-3$ fatty acids (e.g., fish, canola oil, and wheat germ), mainly eicosapentanoic acid and docosahexanoic acid, lead to the formation of less inflammatory eicasanoids (e.g., PGE3, thromboxane A3, and leukotriene B5) [89]. Because prostaglandins derived from marine polyunsaturated fatty acids are usually less aggressive, intake of these fatty acids are expected to reduce dysmenorrhea. Several studies showed that dietary sulpplemen- tation of $\omega-3$ polyunsaturated fatty acids had a beneficial effect on symptoms of dysmenorrhea in young women [90, 91]. Lower consumption of fish, eggs, and fruit was reported to be a risk factor for this pathology together with early menarche, and long and heavy menstrual flow [92]. These facts suggest that fish intake facilitates reduction of dysmenorrhea. Vitamin E may involve a reduction in prostaglandin formation by inhibiting arachidonic acid release [93]. It was reported that dysmenorrhea was significantly reduced by short daily administration of vitamin $\mathrm{E}$ before and during menses [93, 94]. Recently, polyunsaturated fat intake was reported to significantly decrease menstrual cycle length [95].

\section{Phytoestrogens}

It has been reported that meat contains considerable amount of natural sex steroid hormones such as $17 \beta$ estradiol [96], whereas soybeans have isoflavone that possesses estrogenic and antioxidant actions [97, 98]. In general, phytoestrogens are grouped into four main categories: isoflavones, coumestans, lignans, and flavonoids [99]. Soy isoflavones are expected to prevent postmenopausal osteoporosis [100]. However, high short-term isoflavone-containing soy intake had no significant effects on most circulating sex hormones in young healthy women [101]. Supplementation with lignans was reported to increase the length of the luteal phase and the ratio of progesterone to estradiol during the luteal phase [102]. However, Cassidy et al. observed that isoflavones increased the follicular phase without affecting luteal phase length [103]. It was also reported that black soybean has the potential to improve the anovular menstrual cycle [104]. A significant negative correlation between soy isoflavones intake and perimenstrual symptoms was reported [105]. Recent studies showed that catechins, which are abundant in green teas, have cancer preventing effects $[106,107]$. These polyphenols were also demonstrated to modulate estrogen action through molecular mechanisms at the serum concentration after tea-drinking [108,109].

\section{Supplement}

Supplement of FertilityBlend (Daily Wellness Co., Sunnyvale, California), a proprietary nutritional supplement containing chasteberry and green tea extracts, L-arginine, vitamins (including folate) and minerals was shown to increase mean midluteal phase progesterone level and the average number of high temprature days during the luteal phase [110].

In patients with premenstrual syndrome, a daily calcium supplement $(1200 \mathrm{mg}$ ) positively reduced the symptoms ratings [111,112]. A daily magnesium supplement (200 mg) improved fluid retention and mood [113], and a daily supplement of vitamin B6 reduced premenstrual syndrome [114]. In addition, it was also reported that treatment once daily with $20 \mathrm{mg}$ of extract of agnus castus fruit, or chaste berry, reduced irritability, mood changes, rage, headache and breast swelling by $50 \%$ or more [115].

\section{CONCLUSION}

Although epidemiologic evaluation for disturbance of menstrual cycle is important to predict various factors that are associated with women's reproductive function, there is no constant definition of regular or normal menstruation 
since there is considerable variation in menstrual cycles among women. Therefore, researchers should define the optimal range as regular or normal menstruation from the perspectives of the aims and subjects of the study. Accumulating evidence suggests that food customs influence gynecological disorders such as irregular menses, dysmenorrhea and premenstrual syndrome in young women. Accordingly, the relationship between food customs and gynecological disorders is an important issue. These effects of dietary habits on female reproductive functions should be clarified in the future.

\section{REFERENCES}

[1] Fujiwara T, Nakata R. Current problems of food intake in young women in Japan: their influence on female reproductive function. Reprod Med Biol 2004; 3: 107-14.

[2] Smith S, Schiff I. The premenstrual syndrome; Diagnosis and management. Fertil Steril 1989; 52: 527-43.

[3] Cerin A, Collins A, Landgren BM, Eneroth P. Hormonal and biochemical profiles of premenstrual syndrome. Acta Obstet Gynecol Scand 1993; 72: 337-43.

[4] Fujiwara T. Skipping breakfast is associated with dysmenorrhea in young women in Japan. Int J Food Sci Nutr 2003; 54: 505-509.

[5] Carpenter SE. Psychosocial menstrual disorders: stress, exercise and diet's effect on the menstrual cycle. Curr Opin Obstet Gynecol 1994; 6: 536-539.

[6] Renaer M, Vertommen H, Nijs P, Wagemans L, Van Hemelrijck T. Psychological aspects of chronic pelvic pain in women. Am J Obstet Gynecol 1979; 134: 75-80.

[7] Alonso C, Coe CL. Disruptions of social relationships accentuate the association between emotional distress and menstrual pain in young women. Health Psychol 2001; 20: 411-41.

[8] Lloyd T, Schaeffer JM, Walker MA, Demers LM. Urinary hormonal concentrations and spinal bone densities of premenopausal vegetarian and nonvegetarian women. Am J Clin Nutr 1991; 54: 1005-10.

[9] Harlow S, Campbell OMR. Epidemiology of menstrual disorders in developing countries: a systemic review. Br J Obstet Gynaecol 2004; 111: 6-16.

[10] Battaglia C, Pasini A, Mancini F, et al. Utero-ovarian ultrasonographic and Doppler flow analyses in female childhood cancer survivors with regular menstruation and normal circulating folliclestimulating hormone levels. Fertil Steril 2006; 85: 455-61.

[11] Schmittner J, Schroeder JR, Epstein DH, Preston KL. Menstrual cycle length during methadone maintenance. Addition 2005; 100: 829-36.

[12] Ferin MJ. The menstrual cycle: an integrative view. In: Adashi EY, Rock JA, Rosemwaks Z. Ed, Reproductive Endocrinology, Surgery, and Technology. Lipincott-Raven, Philadelphia, 1996: 10321.

[13] Vuorento T, Huhtaniemi I. Daily levels of salivary progesterone during menstrual cycle in adolescent girls. Fertil Steril 1992; 58: 685-90.

[14] Wyshak G, Frisch RE. Evidence for a secular trend in age of menarche. N Engl J Med 1982; 306: 1033-1035.

[15] Zacharias L, Rand WM, Wurtman RJ. A prospective study of sexual development and growth in American girls: the statistics of menarchie. Obstet Gynecol Surv 1976; 31: 325-37.

[16] Harlan WR, Harlan EA, Grillo GP. Secondary sex characteristics of girls 12 to 17 years of age: the U.S. Health Examination Survey. J Pediatr 1980; 96: 1074-8.

[17] Lee PA, Guo SS, Kulin HE. Age of puberty: data from the United States of America. APMIS 2001; 109: 81-88.

[18] Tanner JM. Growth as a monitor of nutritional status. Proc Nutr Soc 1976; 35: 315-22.

[19] Yen SSC. The human menstrual cycle: neuroendocrine regulation. In: Yen SSC, Jaffe RB, Barbieri RL, Eds. Reproductive Endocrinology: Physiology, Pathophysiology, and Clinical Management. Philadelphia: W.B.Saunders Co., 1999: 191-217.

[20] Foster FP. The periodicity and duration of the menstrual flow. New York Med J 1889: 49: 610-611.

[21] Kennedy W. The menarche and menstrual type: Notes on 10000 case records. J Obst Gynaec Brit Emp 1933; 40: 792.
[22] Arey LB. The degree of normal menstrual irregularity: An analysis of 20,000 calendar records from 1,500 individuals. Am J Obstet Gynecol 1939; 37: 12-29.

[23] Haman JO. The length of the menstrual cycle: A study of 150 normal women. Am J Obstet Gynecol 1942; 43: 870-3.

[24] Chiazze LJr, Brayer FT, Macisco JJJr, Parker MP, Duffy BJ. The length and variability of the human menstrual cycle. JAMA 1968; 203: 377-80

[25] Treloar AE, Boynton RE, Behn BG, Brown BW. Variation of the human menstrual cycle through reproductive life. Int J Fertil 1967; 12: $77-126$.

[26] Sherman BM, Korenman SG. Hormonal characteristics of the human menstrual cycle throughout reproductive life. J Clin Invest 1975; 55: 699-706.

[27] Lee SJ, Lenton EA, Sexton L, Cooke ID. The effect of age on the cyclical patterns of plasma LH, FSH, oestradiol and progesterone in women with regular menstrual cycles. Hum Reprod 1988; 3: 851-5.

[28] Hughes EG, Robertson DM, Handelsman DJ, Hayward S, Healy DL, de Kretser DM. Inhibin and estradiol responses to ovarian hyperstimulation: effects of age and predictive value for in vitro fertilization outcome. J Clin Endocrinol Metab 1990; 70: 358-64.

[29] Lenton EA, Landgren BM, Sexton L, Harper R. Normal variation in the length of the follicular phase of the menstrual cycle: effect of chronological age. Br J Obstet Gynaecol 1984; 91: 681-4.

[30] Munster K, Schmidt L, Helm P. Length and variation in the menstrual cycle--a cross-sectional study from a Danish county. Br J Obstet Gynaecol 1992; 99: 422-9.

[31] Reame NK. Female troubles: an analysis of menstrual cycle research in the NINR portfolio as a model for science development in women's health. Annu Rev Nurs Res 2001; 19: 325-337.

[32] Adams-Hillard PJ, Deitch HR. Menstrual disorders in the college age female. Pediatr Clin North Am 2005; 52: 179-197.

[33] Kaewrudee S, Taneepanichskul S. Norplant users with irregular bleeding. Ultrasonographic assessment and evaluation of serum concentrations of estradiol and progesterone. J Reprod Med 2000; 45: 983-6.

[34] Järvelaid M. The effect of gynecologic age, body mass index and psychosocial environment on menstrual regularity among teenaged females. Acta Obstet Gynecol Scand 2005; 84: 645-9.

[35] Schneider MB, Bijur PE, Fisher M, Friedman SB, Toffler CPA. Menstrual irregularity in female military cadets: comparison of data utilizing short-term and long-trem recall. J Pediatr Adolesc Gynecol 2003; 16: 89-93.

[36] Bonamonte D, Foti C, Antelmi AR, et al. Nickel contact allergy and menstrual cycle. Contact Dermatitis 2005; 52: 309-13.

[37] Rowland AS, Baird DD, Long S, et al. Influence of medical conditions and lifestyle factors on the menstrual cycle. Epidemiology 2002; 13: 668-74.

[38] Douchi T, Kuwahara R, Yamamoto S, Oki T, Yamasaki H, Nagata Y. Relationship of upper body obesity to menstrual disorders. Acta Obstet Gynecol Scand 2002; 81: 147-50.

[39] Kennedy S. Primary dysmenorrhea. Lancet 1997; 349: 1116.

[40] Deligeoroglou E. Dysmenorrhea. Ann NY Acad Sci 2000; 900: 237-44.

[41] Dawood MY. Dysmenorrhea and prostaglandins: Pharmacological and therapeutic consideration. Drugs 1981;22: 42.

[42] Lundstrom V, Green K. Endogenous levels of prostaglandin F2 and its main metabolites in plasma and endometrium of normal and dysmenorrheic women. Am J Obstet Gynecol 1978; 130: 640-6.

[43] Speroff L, Glass RH, Kase NG. Menstrual disorders. In Speroff L, Glass RH, Kase NG (Eds). Clinical Gynecologic Endocrinology and Infertility. Baltimore: Williams \& Wilkins, 1994; 515-30.

[44] Renaer M, Vertommen H, Nijs P, Wagemans L \& Van Hemelrijck T. Psychological aspects of chronic pelvic pain in women. Am J Obstet Gynecol 1979; 134: 75-80.

[45] Alonso C, Coe CL. Disruptions of social relationships accentuate the association between emotional distress and menstrual pain in young women. Health Psychol 2001; 20: 411-41.

[46] Fauconnier A, Chapron C. Endometriosis and pelvic pain: epidemiological evidence of the relationship and implications. Hum Reprod Update 2005; 11: 595-606.

[47] Smith S, Schiff I. The premenstrual syndrome; Diagnosis and management. Fertil Steril 1989; 52: 527-543. 
[48] Cerin A, Collins A, Landgren BM, Eneroth P. Hormonal and biochemical profiles of premenstrual syndrome. Acta Obstet Gynecol Scand 1993; 72: 337-43.

[49] Campagne DM, Campagne G. The premenstrual syndrome revisited. Eur J Obstet Gynecol Reprod Biol 2007; 130: 4-17.

[50] Derman O, Kanbur NÖ. Tokur TE, Kutluk T. Premenstrual syndrome and associated symptoms in adolescence girls. Eur J Obstet Gynecol Reprod Boil 2004; 116: 201-6.

[51] American Psychiatric Association. Diagnostic and statistical manual of mental disorders. 4th ed. Washington, DC: American Psychiatric Association; 1994: 714-8.

[52] Fujiwara T. The discrepancy between BMI and self-recognition of adequate body weight may cause insufficient food intake and habits in young women in Japan. Bull Ashiya Coll 2005; 27: 75-80.

[53] Fujiwara T. Diet during adolescence is a trigger for subsequent development of dysmenorrhea in young women. Int $\mathbf{J}$ Food Sci Nutr 2007; 58: 437-44.

[54] Montero P, Bernis C, Fernandes V, Castro S. Influence of body mass index and slimming habits on menstrual pain and cycle irregularity. J Biosoc Sci 1996; 28: 315-23.

[55] Van der Walt LA, Wilmsen EN, Jenkins T. Unsual sex hormone pattern among desert-dwelling hunter-gatherers. J Clin Endocrinol Metab 1978; 46: 658-63.

[56] Bakan R, Birmingham CL, Aeberhardt L, Goldner EM. Dietary zinc intake of vegetarian and nonvegetarian patients with anorexia nervosa. Int J Eat Disord 1993; 13: 229-33.

[57] Brooks SM, Sanborn CF, Albrecht BH, Wagner WW Jr. Diet in athletic amenorrhoea. Lancet 1984; 1: 559-60.

[58] Lloyd T, Schaeffer JM, Walker MA, Demers LM. Urinary hormonal concentrations and spinal bone densities of premenopausal vegetarian and nonvegetarian women. Am J Clin Nutr 1991; 54: 1005-1010.

[59] Pedersen AB, Bartholomew MJ, Dolence LA, Aljadir LP, Netteburg KL, Lloyd T. Menstrual differences due to vegetarian and nonvegetarian diets. Am J Clin Nutr 1991; 53: 879-85.

[60] Pirke KM, Schweiger U, Laessle R, Dickhaut B, Schweiger M, Waechtler M. Dieting influences the menstrual cycle: vegetarian versus nonvegetarian diet. Fertil Steril 1986; 46: 1083-8.

[61] Rose DP, Boyar AP, Cohen C, Strong LE. Effect of a low-fat diet on hormone levels in women with cystic breast disease. I. Serum steroids and gonadotropins. J Natl Cancer Inst 1987; 78: 623-26.

[62] Goldin BR, Woods MN, Spiegelman DL, et al. The effect of dietary fat and fiber on serum estrogen concentrations in premenopausal women under controlled dietary conditions. Cancer 1994; 74: 1125-1131.

[63] Schaefer EJ, Lamon-Fava S, Spiegelman D, et al. Changes in plasma lipoprotein concentrations and composition in response to a low-fat, high-fiber diet are associated with changes in serum estrogen concentrations in premenopausal women. Metabolism 1995; 44: 749-756.

[64] Rose DP, Goldman M, Connolly JM, Strong LE. High-fiber diet reduces serum estrogen concentrations in premenopausal women. Am J Clin Nutr 1991; 54: 520-525.

[65] Woods MN, Gorbach SL, Longcope C, Goldin BR, Dwyer JT, Morrill-LaBrode A. Low-fat, high-fiber diet and serum estrone sulfate in premenopausal women. Am J Clin Nutr 1989; 49: 11791183.

[66] Hagerty MA, Howie BJ, Tan S, Shultz TD. Effect of low- and high-fat intakes on the hormonal milieu of premenopausal women. Am J Clin Nutr 1988; 47: 653-659.

[67] Bagga D, Ashley JM, Geffrey SP, et al. Effects of a very low fat, high fiber diet on serum hormones and menstrual function. Cancer 1995; 76: 2491-2496.

[68] Kaneda N, Nagata C, Kabuto M, Shimizu H. Fat and fiber intakes in relation to serum estrogen concentration in premenopausal Japanese women. Nutr Cancer 1997; 27: 279-83.

[69] Nagata C, Takatsuka N, Kawakami N, Shimizu H. Total and monounsaturated fat intake and serum estrogen concentrations in premenopausal Japanese women. Nutr Cancer 2000; 38: 37-9.

[70] Lattimore PJ, Halford JC. Adolescence and the diet-dieting disparity: healthy food choice or risky health behaviour? Br J Health Psychol 2003; 8: 451-63.

[71] Bendich A. The potential for dietary supplements to reduce premenstrual syndrome (PMS) symptoms. J Am Coll Nutr 2000; 19 : $3-12$.
[72] Kirschner MA. Obesity, androgens, oestrogens, and cancer risk. Cancer Res 1982; 42: 3281-5.

[73] Pasquali R, Pelusi C, Genghini S, Cacciari M, Gambineri A. Obesity and reproductive disorders in women. Hum Reprod Update 2003; 9: 359-72.

[74] Lake JK, Power C, Cole TJ. Women's reproductive health: the role of body mass index in early and adult life. Int $\mathbf{J}$ Obes Relat Metab Disord 1997; 21: 432-8.

[75] Considine RV, Shinba MK, Heiman ML, Kriauciunas A, Stephens TW, Nyce MR. Serum immunoreactive leptin concentrations in normal-weight and obese humans. N Engl J Med 1996; 334: 292-5.

[76] Farooqi IS, Jebb SA, Langmack G, et al. Effects of recombinant leptin therapy in a child with congenital leptin deficiency. $\mathrm{N}$ Engl J Med 1999; 341: 879-84.

[77] Thong FS, Graham TE. Leptin and reproduction: is it a critical link between adipose tissue, nutrition, and reproduction? Can J Appl Physiol 1999; 24: 317-36.

[78] Jones DY. Influence of dietary fat on self-reported menstrual symptoms. Physiol Behav 1987; 40: 483-7.

[79] Barnard ND, Scialli AR, Hurlock D, Bertron P. Diet and sexhormone binding globulin, dysmenorrhea, and premenstrual symptoms. Obstet Gynecol 2000; 95: 245-50.

[80] Dahlgren E, Johansson S, Lindstedt G, et al. Women with polycystic ovary syndrome wedge resected in 1956-65: a long-term followup focusing on natural history and circulating hormones. Fertil Steril 1992; 57: 505-13.

[81] Kousta E, Cela E, Lawrence N, et al. The prevalence of polycystic ovaries in women with a history of gestational diabetes. Clin Endocrinol (Oxf) 2000; 53: 501-7.

[82] Johnson RK, Frary C. Choose beverages and foods to moderate your intake of sugars: 2000 dietary guidelines for Americanswhat's all the fuss about? J Nutr 2001; 131: 2766-71S.

[83] Nagata C, Takatsuka N, Kawakami N, Shimizu H. Association of diet with the onset of menopause in Japanese women. Am J Epidemiol 2000; 152: 863-7.

[84] Rampersaud GC, Pereira MA, Girard BL, Adams J, Metzl JD Breakfast habits, nutritional status, body weight, and academic performance in children and adolescents. J Am Diet Assoc 2005; 105 743-60.

[85] Niemeier HM, Raynor HA, Lloyd-Richardson EE, Rogers ML, Wing RR. Fast food consumption and breakfast skipping: predictors of weight gain from adolescence to adulthood in a nationally representative sample. J Adolesc Health 2006; 39: 842-9.

[86] Schweiger U, Tuschl RJ, Platte P, Broocks A, Laessle RG, Pirke KM. Everyday eating behavior and menstrual function in young women. Fertil Steril 1992; 57: 771-5.

[87] Kunimoto M, Nishi M, Sasaki K. The relation between irregular bowel movement and the lifestyle of working women. Hepatogastroenterology 1998; 45: 956-960.

[88] Fujiwara T. Skipping breakfast induces constipation in young women in Japan. Bull Ashiya Coll 2006; 28: 51-60.

[89] Saldeen P, Saldeen T. Women and $\omega-3$ fatty acids. Obstet Gynecol Surv 2004; 59: 722-30

[90] Deutch B. Menstrual pain in Danish women correlated with low n3 polyunsaturated fatty acid intake. Eur J Clin Nutr 1995; 40: 50816.

[91] Harel Z, Biro FM, Kottenhahn RK, Rosenthal SL. Supplementation with $\omega-3$ polyunsaturated fatty acids in the management of dysmenorrhea in adolescents. Am J Obstet Gynecol 1996; 174: 1335-8.

[92] Balbi C, Musone R, Menditto A, et al. Influence of menstrual factors and dietary habits on menstrual pain in adolescence age. Eur J Obstet Gynecol Reprod Biol 2000; 91: 143-8.

[93] Ziaei S, Zakeri M, Kazemnejad A. A randomized controlled trial of vitamin $\mathrm{E}$ in the treatment of primary dysmenorrhea. Br J Obstet Gynaecol 2005; 112: 466-69.

[94] Ziaei S, Faghihzadeh S, Sohrabvand F, Lamyian M, Ememgholy T. A randomized placebo-controlled trial to determine the efficacy of vitamin $\mathrm{E}$ in treatment of primary dysmenorrhea. Br J Obstet Gynaecol 2001; 108: 1181-3.

[95] Nagata C, Oba S, Shimizu H. Associations of menstrual cycle length with intake of soy, fat, and dietary fiber in Japanese women. Nutr Cancer 2006; 54: 166-70.

[96] Daxenberger A, Ibarreta D, Meyer HHD. Possible health impact of animal oestrogens in food. Hum Reprod Update 2001; 7: 340-55. 
[97] Duffy C, Cyr M. Phytoestrogens: potential benefits and implications for breast cancer survivors. J Womens Health (Larchmt) 2003; 12: 617-31.

[98] Sarkar FH, Li Y. Soy isoflavones and cancer prevention. Cancer Invest 2003; 21: 744-757.

[99] Albertazzi P, Purdie DW. The nature and utility of phytoestrogens: A review of the evidence, Maturitas 2002; 42: 173-85.

[100] Setchell KD, Olsen EL. Dietary phytoestrogens and their effect on bone: evidence from in vitro and in vivo, human observational, and dietary intervention studies. Am J Clin Nutr 2003; 78 (3 Suppl) S 593- 609.

[101] Zittermann A, Geppert J, Baier S, et al. Short-term effects of high soy supplementation on sex hormones, bone markers, and lipid parameters in young female adults. Eur J Nutr 2004; 43: 100-8.

[102] Phipps WR, Martini MC, Lampe JW, Slavin JL, Kurzer MS. Effect of flax seed ingestion on the menstrual cycle. J Clin Endocrinol Metab 1993; 77: 1215-9.

[103] Cassidy A, Bingham S, Setchell KD. Biological effects of a diet of soy protein rich in isoflavones on the menstrual cycle of premenopausal women. Am J Clin Nutr 1994; 60: 333-40

[104] Kohama T, Kobayashi H, Inoue M. The effect of soybeans on the anovulatory cycle. J Med Food 2005; 8: 550-1.

[105] Kim HW, Kwon MK, Kim NS, Reame NE. Intake of dietary soy isoflavones in relation to perimenstrual symptoms of Korean women living in the USA. Nurs Health Sci 2006; 8: 108-13.

[106] Fujiki H, Suganuma M, Imai K, Nakachi K. Green tea: cancer preventive beverage and/or drug. Cancer Lett 2002; 188: 9-13.

[107] Chung FL, Schwartz J, Herzog CR, Yang YM. Tea and cancer prevention: studies in animals and humans. J Nutr 2003; 133(suppl) S3268-3274.
[108] Kuruto-Niwa R, Inoue S, Ogawa S, Muramatsu M, Nozawa R. Effects of tea catechins on the ERE-regulated estrogenic activity. J Agric Food Chem 2000; 48: 6355-61.

[109] Ratna WN, Simonelli JA. The action of dietary phytochemicals quercetin, catechin, resveratrol and naringenin on estrogenmediated gene expression. Life Sci 2002; 70: 1577-89.

[110] Westphal LM, Polan ML, Trant AS, Mooney SB. A nutritional supplement for improving fertility in women: a pilot study. J Reprod Med 2004; 49: 289-93.

[111] Thys-Jacobs S, Starkey P, Bernstein D, Tian J. Calcium carbonate and the premenstrual syndrome: effects on premenstrual and menstrual symptoms. Am J Obstet Gynecol 1998; 179: 444-52.

[112] Bertone-Johnson ER, Hankinson SE, Bendich A, Johnson SR, Willett WC, Manson JE. Calcium and vitamin D intake and risk of incident premenstrual syndrome. Arch Intern Med 2005; 165: 1246-52.

[113] Khine K, Rosenstein DL, Elin RJ, Niemela JE, Schmidt PJ, Rubinow DR. Magnesium $(\mathrm{Mg})$ retention and mood effects after intravenous $\mathrm{Mg}$ infusion in premenstrual dysphoric disorder. Biol Psychiatry $2006 ; 59: 327-33$.

[114] De Souza MC, Walker AF, Robinson PA, Bolland K. A synergistic effect of a daily supplement for 1 month of $200 \mathrm{mg}$ magnesium plus $50 \mathrm{mg}$ vitamin $\mathrm{B} 6$ for the relief of anxiety-related premenstrual symptoms: a randomized, double-blind, crossover study. J Womens Health Gend Based Med 2000; 9: 131-9.

[115] Schellenberg R. Treatment for the premenstrual syndrome with agnus castus fruit extract: prospective, randomized, placebo controlled study. BMJ 2001; 322: 134-7. 